\title{
Analyzing the Critical Risk Factors in Oil and Gas Pipelines Projects Regarding the Perceptions of the Stakeholders
}

\author{
Layth Kraidi $^{\mathrm{a}, \mathrm{b}^{*}}$, Raj Shah ${ }^{\mathrm{a},}$ Wilfred Matipa ${ }^{\mathrm{a}}$ and Fiona Borthwick ${ }^{\mathrm{a}}$ \\ ${ }^{a}$ Department of the Built Environment, Faculty of Engineering and Technology, Liverpool John Moores University. Liverpool, L3 3AF, \\ England, UK \\ ${ }^{b}$ Department of Civil Engineering, College of Engineering, Al Muthanna University, Al Muthanna, Iraq
}

\begin{abstract}
Oil and Gas Pipeline (OGP) projects face a wide range of Risk Factors (RFs) at the design, construction and operational stages of the project particularly because of Third Party Disturbance (TPD) in the insecure environments. The lack of risk information and the root causes of pipelines' failures are hindering the efforts of managing these risks. Therefore, this paper aims to analyze the existing risk factors and recommend an effective Risk Mitigation Methods (RMMs) based on a holistic approach from the prospect of stakeholders' interest. An investigation was carried out to identify the critical RFs and existing RMMs in different circumstances to overcome the problem of the historical records about the RFs and RMMs. The findings of the literature review were used to design a questionnaire survey to analyze RFs and evaluate the "usability and effectiveness" of the RMMs. The RFs were ranked by using Risk Index (RI) method based on the probability and severity levels of each RF. The survey results revealed that sabotage and terrorism as part of TPD, corruption and insecure areas are the most critical RFs, whereas, anti-corrosion efforts, underground pipelines and technologically advanced risk monitoring systems are the most effective RMMs. These ranking are vary based on the occupation of the stakeholder in OGPs; like the planners and the researchers said corruption is the most critical RF, and the researchers said that the advance risk monitoring systems are the most effective RMM.
\end{abstract}

(C) 2018 The Authors. Published by Diamond Congress Ltd., Budapest University of Technology and Economics Peer-review under responsibility of the scientific committee of the Creative Construction Conference 2018.

Keywords: Oil and gas pipelines (OGPs), risk analysis, Stakeholders' perceptions, Risk Mitigation Methods (RMMs)

\section{Introduction}

Oil and Gas Pipelines (OGPs) projects must be planned, designed, installed and operated in ways that comply with the safety requirements. However, several risks are hindering the safety of these projects such as external sabotage, corrosion [1], design and construction defects, natural hazards, operational errors and more risks [2-4]. Mitigating OGPs' RFs is a valuable knowledge because it minimizes the economic losses from disturbing the business of oil export; as well as, it ensures the safety of the projects' stuff and the people that live near the pipelines.

The efforts of mitigating OGPs RFs are significantly require verified historical records about the pipelines' accidents and failure reasons [5,6]. Moreover, the probability of RFs must be accurately analyzed and ranked because dealing with each RF as the most severe risk results resources wistful. However, the existing risk analysis methods are not accurate enough to analyze the external sabotage of the pipelines when there is no database "historical records" about such risk [7-9]. Additionally, an accurate evaluation of the Risk Mitigation Methods (RMMs) in term of their degrees of "usability and effectiveness" degrees of mitigating the RFs helps the decision makers while they are considering their plans to mitigate OGPs' RFs. Accordingly, the inaccurate analyses of OGPs' RFs and inaccurate evaluation of the RMMs are hindering any efforts of risk mitigation in these projects. Particularly, in the troubled and developing

*Corresponding author: Author email: 1.a.kraidi@2016.ljmu.ac.uk 
countries because these highlighted problems are crucial and associate with OGP projects in these countries. Hence, there is a vital need to help the stakeholders to improve the safety for these projects by providing the required data for OGPs risk management such as the "probability and severity" levels of the RFs and the "usability and effectiveness" of the RMMs.

The aim of this paper is to analyze the RFs and evaluate the RMMs in OGPs projects more holistically and effectively base on qualitative documents analysis and a questionnaire survey. Moreover, the up-to-date data about the RFs and RMMs can help the stakeholders to improve the safety of GOPs continuously.

Iraq is selected as the case study in this paper because its oil reserves is the fifth-largest oil reserves in the world [10]. As well as, it are estimated that Iraq's gas reserves are amongst $10^{\text {th }}$ to $13^{\text {th }}$ largest reserves globally, in addition to vast potential reserves for further discoveries [11]. At the present time, a vast range of RFs threatens OGPs project in Iraq and the inadequacy of mitigating the RFs hinders the business of oil export which is in high demand after 2003.

Moving forward in this paper, section 2 consists a review about identifying pipelines' RFs and RMMs. Section 3 explains the research methodology. The results of analyzing the RFS and evaluating RMMs are interpreted in section 4. Section 5 discusses this paper' findings. Finally, section 6 shows the conclusions.

\section{Identifying the Risk Factors (RFs) and Risk Mitigation Methods (RMMs) in OGPs Projects}

Qualitative documents analysis were carried out to identify the RFs in OGPs projects in different circumstances, especially in the insecure countries. Thirty RFs were identified based on the findings of the literature review that are shown in Table 1.

Table 1. The identified RFs in OGPs projects from the literature review.

\begin{tabular}{ll}
\hline RFs & Author \\
\hline Thieves & 12 \\
Publics' legal and moral awareness about OGPs projects & 7 \\
Peoples' education and poverty levels in OGPs areas & 12 \\
Leakage of sensitive information & 13 \\
Threats to staff & 14 \\
Sabotage and Terrorism & 12 \\
Accessibility of pipelines & 15 \\
Conflict over land ownership & 16 \\
Insecure areas & 15 \\
Vehicle accidents & 7 \\
Animal accidents & 17 \\
Geological RFs & 18 \\
Lack of regular inspections and maintenance of OGPs & 12 \\
The opportunity to sabotage exposed pipelines "aboveground pipelines" & 14 \\
Lack of compliance with the safety regulations & 18 \\
Weather conditions and natural disasters & 12 \\
Inadequate risk management approaches & 12 \\
Non-availability of warning signs & 12 \\
Weak ability to identify and monitor the RFs & 12 \\
Corrosion and lack of anti-corrosive action & 12 \\
Shortage of modern IT services & 12 \\
Design, construction and material defects & 18 \\
Hacker attacks on the operating or control systems & 15 \\
Operational errors & 12 \\
Corruption & 12 \\
Few researchers about this problem & 12 \\
Lawlessness & 7 \\
Lack of proper training schemes & 12 \\
No proper attention from the stakeholders & 12 \\
Lack of historical records and data about RFs & 12 \\
\hline
\end{tabular}

These wide investigations helped to overcome the problem of data scarcity about the RFs in OGPs projects in Iraq. Accordingly, a number of RMMs was suggested to mitigate RFs like anti-corrosion and cathodic protection; laying the pipelines underground rather than aboveground; modern equipment to monitor the RFs; proper inspection and maintenance; proper training for the stuff about mitigation the RFs in their projects; avoid insecure areas; anti-terrorism planning and design; avoid the registered RFs; protective barriers; government-public cooperation; and warning signs near the pipelines and marker tape above the pipeline. 
Table 1 cannot give accurate information about the "probability and severity" of the RFs. As well as, the suggested RMMs need to be evaluated regarding their degrees of "usability and effectiveness" to mitigate the RFs in OGPs projects. Therefore, the filed investigations were required to analyze the contents of OGPs' safety in Iraq by distributing a questionnaire survey.

\section{Methodology}

An industry-wide questionnaire survey was designed based on the findings of the literature review (see Table 1) in order to analyze the RFs based on the perceptions of the stakeholders in OGPs in Iraq. In this survey, the RMMs will be evaluated too. The respondents were promised that the data will be anonymity analyzed.

The first question was asked about the occupation of the respondents in OGPs projects. The survey had two questions to analyze the RFs as follows. The first question was addressed to analyze the probability of occurrence of the $30 \mathrm{RFs}$ on a five-point rating Likert scales which is "rare, unlikely, possible, likely and almost certain". The second question was analyze to evaluate the severity of the RFs on a scale "negligible, minor, moderate, major and catastrophic". Similarly, the survey had two questions to evaluate the RMMs as follows. The first question was asked about evaluating the usability of the RMMs on a scale "rare, unlikely, possible, likely and almost certain". The second question was about evaluating the effectiveness of RMMs on a scale "ineffective, slightly effective, moderately effective, very effective, and extremely effective".

The descriptive statistical analysis in Statistical Package for the Social Sciences (SPSS) software was used to determine the values of Risk Probability (RP) and Risk Severity (RS) for each RF by calculating the mean of the five point Likert scales. The degree of impact for each RF was found by using Risk Index (RI) method as explained in Eq. (1) [19]. The RFs were ranked regarding their RI values. In the same way, the usability and the effectiveness of the RMMs were found.

$$
R I=(R P \times R S) / 5
$$

\section{Results}

The survey was distributed online and it was targeting the owners, clients, researchers, consultants, planners, designers, and construction, operators, maintenance workers in Iraq's OGPs projects. 198 respondents from stakeholders have answered the survey's questions as shown in

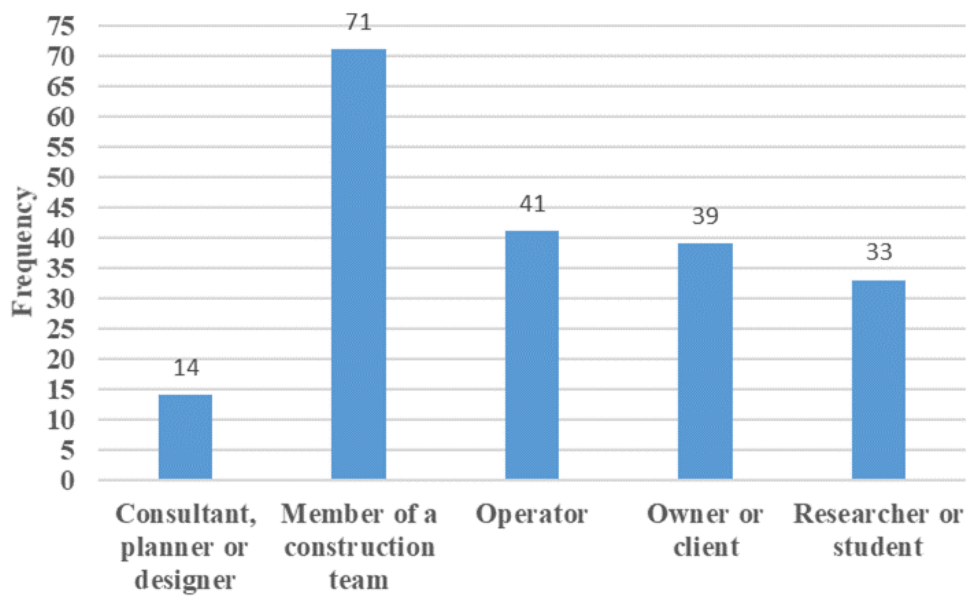

Fig. 1: Participants' demographic information.

Fig 1. As shown in Fig. 1, the majority of the participants were members of construction teams, followed by the operators, owners or clients, researchers or students and the less majority was for the consultants, planners and designers.

The Cronbach's alpha correlation coefficient factor was calculated to measure the reliability level of the survey [20,21]. Commonly 0.7 indicates a minimum level of reliability [22]. Table 2 shows the Cronbach's alpha coefficient 
factor case processing summary. The reliability test is not applicable for question 1 because it was asking about the participants' occupation in OGPs projects.

Table 2. Cronbach's alpha coefficient factor case processing summary for the survey overall and by participants' occupation.

\begin{tabular}{lccc}
\hline Case Processing Summary & Valid $\%$ & Items & $\alpha$ \\
\hline All the questionnaire's questions & 100 & 95 & 0.910 \\
\hline The question about RP (survey overall) & 100 & 30 & 0.919 \\
\hline The question about RS (survey overall) & 100 & 30 & 0.863 \\
\hline The question about the usability of RMMs (survey overall) & 100 & 12 & 0.867 \\
\hline The question about the effectiveness of RMMs (survey overall) & 100 & 12 & 0.792 \\
\hline a consultant, planner or designer & 100.0 & 95 & 0.863 \\
\hline a member of a construction team & 100.0 & 95 & 0.892 \\
\hline an operator & 100.0 & 95 & 0.927 \\
\hline an owner or client & 100.0 & 95 & 0.917 \\
\hline a researcher or student & 100.0 & 95 & 0.899 \\
\hline
\end{tabular}

Based on the occupations of the stakeholder in OGPs projects in Iraq, Table 3, Table 4 and Table 5 show the results of calculating the RP, RS and RI of each RF respectively. Table 6 shows the ranking of the RFs based on their values of RI. The usability and effectiveness of the RMMs are shown in Table 7 and Table 8 respectively. Please note in these tables means the whole participants; (I) means the consultants, planners and designers; (II) means the construction workers; (III) means the operation and maintenance workers; (IV) means the owner and client; and (V) means the researchers.

Table 3. The probability of the risk factors by participants' occupation.

\begin{tabular}{|c|c|c|c|c|c|c|}
\hline \multirow[t]{2}{*}{ RFs } & \multicolumn{6}{|c|}{ (Risk Probability) RP } \\
\hline & Total & I & II & III & IV & $\mathrm{V}$ \\
\hline Terrorism \& sabotage & 3.995 & 3.357 & 3.958 & 4.195 & 4.000 & 4.091 \\
\hline Corruption & 3.980 & 4.000 & 3.986 & 3.878 & 3.846 & 4.242 \\
\hline Insecure areas & 3.717 & 3.286 & 3.634 & 3.805 & 3.769 & 3.909 \\
\hline Low public legal \& moral awareness & 3.712 & 4.000 & 3.761 & 3.561 & 3.513 & 3.909 \\
\hline Thieves & 3.692 & 3.214 & 3.845 & 3.659 & 3.564 & 3.758 \\
\hline Corrosion \& lack protection against it & 3.687 & 3.429 & 3.648 & 3.390 & 3.795 & 4.121 \\
\hline Improper safety regulations & 3.687 & 3.643 & 3.662 & 3.561 & 3.872 & 3.697 \\
\hline Exposed pipelines & 3.667 & 3.429 & 3.437 & 3.854 & 3.897 & 3.758 \\
\hline Shortage of the IT services \& modern equipment & 3.667 & 3.643 & 3.592 & 3.585 & 3.615 & 4.000 \\
\hline Improper inspection \& maintenance & 3.657 & 3.571 & 3.606 & 3.537 & 3.769 & 3.818 \\
\hline Lack of proper training & 3.646 & 3.571 & 3.761 & 3.439 & 3.462 & 3.909 \\
\hline Weak ability to identify \& monitor the threats & 3.631 & 3.571 & 3.577 & 3.561 & 3.692 & 3.788 \\
\hline The pipeline is easy to access & 3.631 & 3.571 & 3.563 & 3.732 & 3.538 & 3.788 \\
\hline Limited warning signs & 3.626 & 3.429 & 3.648 & 3.341 & 3.974 & 3.606 \\
\hline Little researches on this topic & 3.621 & 3.429 & 3.789 & 3.366 & 3.359 & 3.970 \\
\hline Lawlessness & 3.606 & 3.786 & 3.676 & 3.268 & 3.795 & 3.576 \\
\hline Lack of risk registration & 3.566 & 3.214 & 3.606 & 3.390 & 3.615 & 3.788 \\
\hline Stakeholders are not paying proper attention & 3.530 & 3.286 & 3.676 & 3.439 & 3.462 & 3.515 \\
\hline Conflicts over land ownership & 3.495 & 3.571 & 3.451 & 3.659 & 3.667 & 3.152 \\
\hline Public's poverty \& education level & 3.449 & 3.357 & 3.521 & 3.439 & 3.256 & 3.576 \\
\hline Design, construction \& material defects & 3.333 & 2.429 & 3.254 & 3.293 & 3.385 & 3.879 \\
\hline Threats to staff & 3.323 & 2.714 & 3.394 & 3.268 & 3.410 & 3.394 \\
\hline Inadequate risk management & 3.227 & 2.929 & 3.183 & 2.976 & 3.436 & 3.515 \\
\hline Operational errors & 3.101 & 2.857 & 3.042 & 2.878 & 3.205 & 3.485 \\
\hline Leakage of sensitive information & 2.980 & 2.643 & 3.070 & 2.707 & 2.949 & 3.303 \\
\hline Geological risks & 2.747 & 2.714 & 2.662 & 2.537 & 2.795 & 3.152 \\
\hline Natural disasters \& weather conditions & 2.652 & 2.429 & 2.606 & 2.537 & 2.692 & 2.939 \\
\hline Vehicles accidents & 2.465 & 2.357 & 2.380 & 2.293 & 2.333 & 3.061 \\
\hline Hacker attacks on the operating or control system & 2.237 & 1.929 & 2.268 & 2.024 & 2.179 & 2.636 \\
\hline Animals accidents & 1.894 & 1.929 & 1.986 & 1.561 & 1.821 & 2.182 \\
\hline
\end{tabular}


Table 4: The severity of the risk factors by participants' occupation.

\begin{tabular}{|c|c|c|c|c|c|c|}
\hline \multirow[b]{2}{*}{ RFs } & \multicolumn{6}{|c|}{ (Risk Severity) RS } \\
\hline & Total & I & II & III & IV & $\mathrm{V}$ \\
\hline Terrorism \& sabotage & 4.490 & 3.571 & 3.732 & 3.829 & 3.718 & 3.939 \\
\hline Corruption & 4.323 & 3.500 & 3.958 & 3.57 & 3.692 & 3.636 \\
\hline Lawlessness & 4.192 & 3.286 & 3.732 & 3.512 & 3.769 & 3.939 \\
\hline Insecure areas & 4.106 & 3.286 & 3.634 & 3.659 & 4.000 & 3.606 \\
\hline Thieves & 4.081 & 3.000 & 3.662 & 3.585 & 3.846 & 3.818 \\
\hline Corrosion \& lack protection against it & 3.990 & 3.357 & 3.676 & 3.683 & 3.641 & 3.697 \\
\hline Stakeholders are not paying proper attention & 3.960 & 3.143 & 3.577 & 3.829 & 3.692 & 3.727 \\
\hline Improper safety regulations & 3.949 & 3.214 & 3.592 & 3.488 & 3.872 & 3.667 \\
\hline Improper inspection \& maintenance & 3.924 & 3.357 & 3.746 & 3.610 & 3.641 & 3.394 \\
\hline Weak ability to identify \& monitor the threats & 3.899 & 3.000 & 3.690 & 3.488 & 3.487 & 3.758 \\
\hline Low public legal \& moral awareness & 3.859 & 3.357 & 3.535 & 3.244 & 3.590 & 3.727 \\
\hline Design, construction \& material defects & 3.848 & 3.571 & 3.549 & 3.390 & 3.179 & 3.333 \\
\hline Lack of proper training & 3.773 & 3.500 & 3.408 & 3.098 & 3.410 & 3.697 \\
\hline Threats to staff & 3.732 & 2.857 & 3.014 & 3.293 & 3.128 & 3.606 \\
\hline Lack of risk registration & 3.697 & 2.857 & 3.042 & 2.854 & 3.077 & 3.455 \\
\hline Exposed pipelines & 3.682 & 2.500 & 3.042 & 2.951 & 3.000 & 3.000 \\
\hline Limited warning signs & 3.662 & 2.143 & 2.676 & 2.780 & 2.846 & 2.788 \\
\hline Shortage of the IT services \& modern equipment & 3.652 & 1.714 & 2.155 & 1.951 & 2.000 & 1.970 \\
\hline The pipeline is easy to access & 3.646 & 3.571 & 3.732 & 3.829 & 3.718 & 3.939 \\
\hline Operational errors & 3.611 & 3.500 & 3.958 & 3.537 & 3.692 & 3.636 \\
\hline Conflicts over land ownership & 3.611 & 3.286 & 3.732 & 3.512 & 3.769 & 3.939 \\
\hline Little researches on this topic & 3.571 & 3.286 & 3.634 & 3.659 & 4.000 & 3.606 \\
\hline Leakage of sensitive information & 3.505 & 3.000 & 3.662 & 3.585 & 3.846 & 3.818 \\
\hline Public's poverty \& education level & 3.409 & 3.357 & 3.676 & 3.683 & 3.641 & 3.697 \\
\hline Inadequate risk management & 3.399 & 3.143 & 3.577 & 3.829 & 3.692 & 3.727 \\
\hline Geological risks & 3.182 & 3.214 & 3.592 & 3.488 & 3.872 & 3.667 \\
\hline Natural disasters \& weather conditions & 3.066 & 3.357 & 3.746 & 3.610 & 3.641 & 3.394 \\
\hline Hacker attacks on the operating or control system & 2.970 & 3.000 & 3.690 & 3.488 & 3.487 & 3.758 \\
\hline Vehicles accidents & 2.712 & 3.357 & 3.535 & 3.244 & 3.590 & 3.727 \\
\hline Animals accidents & 2.020 & 3.571 & 3.549 & 3.390 & 3.179 & 3.333 \\
\hline
\end{tabular}

Table 5. The index of the risk factors by participants' occupation.

\begin{tabular}{|c|c|c|c|c|c|c|}
\hline \multirow[t]{2}{*}{ RFs } & \multicolumn{6}{|c|}{ (Risk Index) RI } \\
\hline & Total & $\mathrm{I}$ & II & III & IV & $\mathrm{V}$ \\
\hline Terrorism \& sabotage & $3.587^{*}$ & 3.021 & 3.579 & 3.909 & 3.405 & 3.669 \\
\hline Corruption & 3.441 & 3.314 & 3.537 & 3.254 & 3.314 & 3.677 \\
\hline Insecure areas & 3.053 & 2.722 & 2.928 & 3.267 & 3.035 & 3.222 \\
\hline Lawlessness & 3.023 & 2.812 & 3.210 & 2.583 & 3.211 & 3.056 \\
\hline Thieves & 3.013 & 2.388 & 3.206 & 2.998 & 2.906 & 3.029 \\
\hline Corrosion \& lack protection against it & 2.942 & 2.498 & 2.918 & 2.696 & 3.172 & 3.222 \\
\hline Improper safety regulations & 2.912 & 2.810 & 2.899 & 2.797 & 2.958 & 3.070 \\
\hline Improper inspection \& maintenance & 2.870 & 2.755 & 2.742 & 2.829 & 3.015 & 3.078 \\
\hline Publics' legal and moral awareness & 2.865 & 3.086 & 2.934 & 2.588 & 2.738 & 3.127 \\
\hline Weak ability to identify $\&$ monitor the threats & 2.832 & 2.551 & 2.802 & 2.831 & 2.878 & 2.961 \\
\hline Stakeholders are not paying proper attention & 2.796 & 2.629 & 2.972 & 2.583 & 2.716 & 2.855 \\
\hline Lack of proper training & 2.751 & 2.551 & 2.807 & 2.634 & 2.574 & 3.080 \\
\hline Exposed pipelines & 2.700 & 2.253 & 2.498 & 2.820 & 3.118 & 2.710 \\
\hline Shortage of the IT services \& modern equipment & 2.678 & 2.446 & 2.641 & 2.641 & 2.633 & 2.958 \\
\hline Limited warning signs & 2.656 & 2.057 & 2.672 & 2.396 & 3.057 & 2.754 \\
\hline The pipeline is easy to access & 2.648 & 2.245 & 2.550 & 2.858 & 2.613 & 2.824 \\
\hline Lack of risk registration & 2.636 & 2.112 & 2.692 & 2.381 & 2.725 & 2.984 \\
\hline Little researches on this topic & 2.586 & 2.057 & 2.796 & 2.348 & 2.343 & 2.983 \\
\hline Design, construction \& material defects & 2.566 & 1.839 & 2.410 & 2.538 & 2.760 & 3.033 \\
\hline Conflicts over land ownership & 2.524 & 2.398 & 2.586 & 2.641 & 2.670 & 2.139 \\
\hline Threats to staff & 2.481 & 1.900 & 2.687 & 2.312 & 2.518 & 2.468 \\
\hline The education and poverty levels in OGPs areas & 2.352 & 2.398 & 2.500 & 2.332 & 2.071 & 2.384 \\
\hline Operational errors & 2.240 & 1.837 & 2.185 & 2.008 & 2.482 & 2.556 \\
\hline Inadequate risk management & 2.194 & 2.050 & 2.170 & 1.843 & 2.343 & 2.599 \\
\hline Leakage of sensitive information & 2.089 & 1.774 & 2.171 & 1.756 & 2.117 & 2.462 \\
\hline Geological risks & 1.748 & 1.551 & 1.605 & 1.670 & 1.749 & 2.273 \\
\hline Natural disasters \& weather conditions & 1.626 & 1.388 & 1.585 & 1.448 & 1.657 & 2.031 \\
\hline Vehicles accidents & 1.337 & 1.010 & 1.274 & 1.275 & 1.328 & 1.707 \\
\hline Hacker attacks on the operating or control system & 1.329 & 0.964 & 1.380 & 1.195 & 1.308 & 1.582 \\
\hline Animals accidents & 0.765 & 0.661 & 0.856 & 0.609 & 0.728 & 0.860 \\
\hline
\end{tabular}


Table 6: The ranking of the RFs by participants' occupation.

\begin{tabular}{lllllll}
\hline & \multicolumn{5}{c}{ RFs } & \multicolumn{5}{c}{ Raning the RFs } \\
\cline { 2 - 7 } & Total & I & II & III & IV & V \\
\hline Terrorism \& sabotage & 1 & 3 & 1 & 1 & 1 & 2 \\
Corruption & 2 & 1 & 2 & 3 & 2 & 1 \\
Insecure areas & 3 & 7 & 7 & 2 & 7 & 4 \\
Lawlessness & 4 & 4 & 3 & 16 & 3 & 9 \\
Thieves & 5 & 15 & 4 & 4 & 10 & 11 \\
Corrosion \& lack protection against it & 6 & 11 & 8 & 10 & 4 & 3 \\
Improper safety regulations & 7 & 5 & 9 & 9 & 9 & 8 \\
Improper inspection \& maintenance & 8 & 6 & 13 & 7 & 8 & 7 \\
Publics' legal and moral awareness & 9 & 2 & 6 & 14 & 13 & 5 \\
Weak ability to identify \& monitor the threats & 10 & 10 & 11 & 6 & 11 & 14 \\
Stakeholders are not paying proper attention & 11 & 8 & 5 & 15 & 15 & 16 \\
Lack of proper training & 12 & 9 & 10 & 13 & 19 & 6 \\
Exposed pipelines & 13 & 16 & 21 & 8 & 5 & 19 \\
Shortage of the IT services \& modern equipment & 14 & 12 & 17 & 12 & 17 & 15 \\
Limited warning signs & 15 & 20 & 16 & 18 & 6 & 18 \\
The pipeline is easy to access & 16 & 17 & 19 & 5 & 18 & 17 \\
Lack of risk registration & 17 & 18 & 14 & 19 & 14 & 12 \\
Little researches on this topic & 18 & 19 & 12 & 20 & 23 & 13 \\
Design, construction \& material defects & 19 & 23 & 22 & 17 & 12 & 10 \\
Conflicts over land ownership & 20 & 14 & 18 & 11 & 16 & 26 \\
Threats to staff & 21 & 22 & 15 & 22 & 20 & 22 \\
The education and poverty levels in OGPs areas & 22 & 13 & 20 & 21 & 25 & 24 \\
Operational errors & 23 & 24 & 23 & 23 & 21 & 21 \\
Inadequate risk management & 24 & 21 & 25 & 24 & 22 & 20 \\
Leakage of sensitive information & 25 & 25 & 24 & 25 & 24 & 23 \\
Geological risks & 26 & 26 & 26 & 26 & 26 & 25 \\
Natural disasters \& weather conditions & 27 & 27 & 27 & 27 & 27 & 27 \\
Vehicles accidents & 28 & 28 & 29 & 28 & 28 & 28 \\
Hacker attacks on the operating or control system & 29 & 29 & 28 & 29 & 29 & 29 \\
Animals accidents & 30 & 30 & 30 & 30 & 30 & 30 \\
\hline
\end{tabular}

Table 7 . The usability degree of each RMM by participants' occupation.

\begin{tabular}{lllllll}
\hline RMMs & \multicolumn{5}{c}{ Usability } \\
\cline { 2 - 7 } & Total & I & II & III & IV & V \\
\hline Avoid "Insecure-Zones & 3.652 & 2.929 & 3.789 & 3.829 & 3.385 & 3.758 \\
Anti-terrorism design & 3.475 & 2.643 & 3.676 & 3.268 & 3.564 & 3.545 \\
Avoid the registered risks and threats & 3.616 & 3.357 & 3.662 & 3.634 & 3.513 & 3.727 \\
Proper training & 3.768 & 3.643 & 3.634 & 3.854 & 3.769 & 4.000 \\
Move to an underground pipeline & 4.051 & 3.857 & 4.085 & 4.390 & 3.846 & 3.879 \\
Anti-corrosion such as isolation and cathodic protection & 4.247 & 4.000 & 4.282 & 4.512 & 4.103 & 4.121 \\
Protective barriers and perimeter fencing & 3.783 & 3.214 & 3.732 & 3.878 & 3.872 & 3.909 \\
Warning signs and marker tape above the pipeline & 3.727 & 3.143 & 3.732 & 3.683 & 3.846 & 3.879 \\
Foot and vehicles patrols & 3.606 & 3.143 & 3.648 & 3.683 & 3.590 & 3.636 \\
High technology and professional remote monitoring & 3.480 & 2.643 & 3.606 & 3.415 & 3.359 & 3.788 \\
Government-public cooperation & 3.278 & 3.000 & 3.183 & 3.463 & 3.205 & 3.455 \\
Proper inspection, tests and maintenance & 3.677 & 3.429 & 3.549 & 3.805 & 3.769 & 3.788 \\
\hline
\end{tabular}

Table 8 . The effectiveness degree of each RMM by participants' occupation.

\begin{tabular}{lllllll}
\hline RMMs & \multicolumn{7}{c}{ Effectiveness } \\
& Total & I & II & III & IV & V \\
\hline Anti-corrosion such as isolation \& cathodic protection & 4.232 & 3.857 & 4.113 & 4.415 & 4.513 & 4.091 \\
Move to an underground pipeline & 4.066 & 3.929 & 4.000 & 4.220 & 4.333 & 3.758 \\
High technology \& professional remote monitoring & 3.995 & 3.643 & 4.070 & 3.878 & 4.000 & 4.121 \\
Proper inspection, tests \& maintenance & 3.828 & 3.429 & 3.887 & 3.829 & 3.872 & 3.818 \\
Proper training & 3.793 & 3.857 & 3.662 & 3.780 & 3.897 & 3.939 \\
Avoid "Hot-Zones & 3.778 & 3.214 & 4.014 & 3.659 & 3.744 & 3.697 \\
Anti-terrorism design & 3.778 & 3.143 & 3.986 & 3.341 & 4.179 & 3.667 \\
Avoid the registered risks \& threats & 3.773 & 3.500 & 3.817 & 3.683 & 4.000 & 3.636 \\
Protective barriers \& perimeter fencing & 3.682 & 3.214 & 3.577 & 3.756 & 3.872 & 3.788 \\
Warning signs \& marker tape above the pipeline & 3.571 & 2.929 & 3.577 & 3.439 & 3.923 & 3.576 \\
Government-public cooperation & 3.545 & 3.214 & 3.563 & 3.561 & 3.564 & 3.606 \\
Foot \& vehicles patrols & 3.530 & 3.429 & 3.563 & 3.634 & 3.615 & 3.273 \\
\hline
\end{tabular}




\section{Discussion}

By using the RI to rank the RFs, the overall results of the survey show that the terrorism and sabotage, corruption, insecure areas, lawlessness and thefts are the most critical RFs in OGPs projects in Iraq. Nevertheless, the ranking of the RFs is quite varied deepening on the occupations of the stakeholders. Regarding the planners, consultants and designers perceptions corruption, low public legal and moral awareness, sabotage actions, lawlessness and improper safety regulations are the top five RFs that influence the pipeline projects. The stakeholders who are working in the construction filed have ranked the top five of RFs as follows. Terrorism and sabotage actions, corruption, lawlessness, corrosion and lack protection against it, thefts and the stakeholders are not paying proper attention. The operators have come with different ranking as follows. Terrorism and sabotage actions, insecure areas, corruption, thefts, and the pipelines are easy to access. The projects' owners and clients have said that the terrorism and sabotage actions, corruption, lawlessness, corrosion and lack protection against it, and the exposed "aboveground" pipelines are the top five RFs. The participants from the academic field indicated that corruption, terrorism and sabotage actions, corrosion and lack protection against it, insecure areas and low public legal and moral awareness the most critical RFs.

Regarding evaluating the RMMs by their degree of usability, the overall results of the survey indicate anti-corrosion such as isolation and cathodic protection, move to an underground pipeline and protective barriers and perimeter fencing are the RMMs with the higher chance of usability in OGP projects in Iraq. The planners, consultants and designers have another point of view, which is anti-corrosion such as isolation and cathodic protection, move to an underground pipeline, and proper training are the mitigation methods with the higher rate of usability. Anti-corrosion such as isolation and cathodic protection, move to an underground pipeline and avoid "Insecure-Zones" are the more useable methods as construction said. The operators came with a different observation that is like this anti-corrosion such as isolation and cathodic protection, move to an underground pipeline and protective barriers and perimeter fencing are the most useable methods. Which slightly different for the owners and clients observations that are as follows: the methods of the higher rate of usability are anti-corrosion such as isolation and cathodic protection, protective barriers and perimeter fencing and move to an underground pipeline. The researchers said that the anticorrosion such as isolation and cathodic protection, proper training and protective barriers and perimeter fencing are the most usable risk mitigation methods.

The result of evaluating the effectiveness of the RMMs are anti-corrosion such as isolation and cathodic protection, move to an underground pipeline and high technology and professional remote monitoring are the most effective RMMs. However, move to an underground pipeline, anti-corrosion such as isolation and cathodic protection and proper training are the most effective RMMs as the consultants, planners and designers said. Which is different from the observation of the construction teams that are as follows. Anti-corrosion such as isolation and cathodic protection, high technology and professional remote monitoring and avoid "Insecure-Zones are the most effective RMMs. The opinion of the operators is like that anti-corrosion such as isolation and cathodic protection, move to an underground pipeline and high technology and professional remote monitoring are the most effective RMMs. Which is different from the opinions of the owners and clients as they said anti-corrosion such as isolation and cathodic protection, move to an underground pipeline and anti-terrorism design are the most effective RMMs. The researchers think like that high technology and professional remote monitoring, anti-corrosion such as isolation and cathodic protection and proper training are the most effective RMMs.

The survey results were found to be reliable as all Cronbach's alpha coefficient factor values are above 0.7, as explained in Table 2. Collecting the required information from various and trusted sources such as research articles and stakeholders provides real information for OGPs risk management. However, it depends on the availability of such documents and the willingness of the stakeholders to cooperate with the authors. Analyzing the RFs and evaluating the RMMs based on the perceptions of the stakeholders could reduce the time and the cost of the investigations and increase the stakeholders' awareness about their responsibilities regarding OGPs risk management. As well as, it helps to analyze OGPs RFs more realistically and to identify the positive and negative recommendations about RMMs in a way that ensure the continuity of pipeline security. Because the perceptions of the stakeholders are based on real experience about OGPs issues. Furthermore, correct sampling and representing the whole stakeholders' categories enhances the results of RFs analysis and RMMs evaluation.

\section{Conclusion}

There is a need for an accurate analysis of OGPs RFs because the external RFs have not been accurately analyzed yet. The overall results of the survey showed that the external risk factors like terrorism and sabotage, corruption, 
insecure areas, lawlessness and thieves were found the most critical risks in OOPs projects in Iraq. Avoid "InsecureZones, anti-terrorism design and avoid the registered risks and threats were found as the most usable risk mitigation methods. Meanwhile, anti-corrosion such as isolation \& cathodic protection, move to an underground pipeline and high technology \& professional remote monitoring were the most effective risk mitigation methods. While, regarding their occupations in OGPs, the stakeholders in OGPs have different perceptions about this ranking.

This paper provided verified information about risk factor and risk mitigation methods such identifying the risk factors, analyzing the factors" "probability and severity" and evaluating the "usability and the effectiveness" of the risk mitigation methods. Such information could the help organizations and countries that just began to mitigate OGPs risk factors more effectively and to provide useful recommendations for their actions and plans about OGPs risk management in the insecure countries such as Iraq.

\section{Acknowledgement}

The support of the financial sponsor "The Ministry of Higher Education and Scientific Research in Iraq" is highly appreciated by the authors.

\section{References}

[1] T. O. Miesner, \& W. L. Leffler, Oil \& Gas Pipelines in Nontechnical Language, USA, PennWell Corp, 2006.

[2] C. Wan, \& A. Mita, Recognition of potential danger to buried pipelines based on sounds, J. of International Assocaition for Structrual Control and Health Monitoring, 17 (2010) 317-337.

[3] J. Focke, Localization and identification of external INTERFERENCE on pipelines and methods for prevention, 4th Pipeline Technology Conference 2009. Hannover, Germany.

[4] J. Williamson, \& C. Daniel, Third party Major Accident Hazard Pipeline (MAHP) infringement A case study Prepared by the Health and Safety Laboratory for the Health and Safety Executive, 2008.

[5] A. Yazdani-Chamzini, Proposing a new methodology based on fuzzy logic for tunnelling risk assessment, J. of Civil Engineering and Management, 20 (2014) 82-94.

[6] A. Srivastava, \& J. P. Gupta, New methodologies for security risk assessment of oil and gas industry; J. Process Safety and Environmental Protection, 88 (2010) 407-412.

[7] X. Y. Peng, D. C. Yao, G. C. Liang, J. S. Yu, \& S. He, Overall reliability analysis on oil/gas pipeline under typical third-party actions based on fragility theory, J. of Natural Gas Science and Engineering, 34 (2016) 993-1003.

[8] D. Ge, M. Lin, Y. Yang, R. Zhang \& Q. \& Chou, Reliability analysis of complex dynamic fault trees based on an adapted K.D. Heidtmann algorithm; proceedings of the Institution of Mechanical Engineers, Part O , J. of Risk and Reliability, 229(6) (2015) 576-586.

[9] N. Khakzad, F. Khan, P. Amyotte, Safety analysis in process facilities: Comparison of fault tree and Bayesian network approaches, J. Reliability Engineering \& System Safety, 96(8) (2011) 925-932.

[10] Energy Information Administration (E.I.A.), Country Analysis Brief: Iraq: U.S. Energy Information Administration, (2015), Available at https://www.eia.gov/beta/international/analysis_includes/countries_long/Iraq/iraq.pdf

[11] International Energy Agency (I.E.A.) World energy outlook special report. France International Energy Agency, (2013), Available at https://www.iea.org/publications/freepublications/publication/WEO_2012_Iraq_Energy_OutlookFINAL.pdf

[12] U. Nnadi, Z. El-Hassan, D. Smyth, \& J. Mooney, Lack of proper safety management systems in Nigeria oil and gas pipelines. Delta, 2007, 13th. IChemE, SYMPOSIUM SERIES NO 159, HAZARDS 24, 1999.

[13] W.S. Wu, C.F.Yang, J. C. Chang, P.A. Château, \& Y. C. Chang, Risk assessment by integrating interpretive structural modeling and Bayesian network, case of offshore pipeline project, J. Reliability Engineering \& System Safety, 142 (2015) 515-524.

[14] A. Rowland, GIS-based prediction of pipeline third-party interference using hybrid multivariate statistical analysis, PhD thesis, School of Marine Science and Technology, Newcastle University, Newcastle, UK (2011).

[15] A. Srivastava \& J. Gupta, New methodologies for security risk assessment of oil and gas industry, J. process safety and environmental protection, 88(6), (2010) 407-412.

[16] k. Macdonald \& A. Cosham, Best practice for the assessment of defects in pipelines-gouges and dents, J. Engineering Failure Analysis, 12(5), (2005) $720-745$.

[17] S. Mubin \& G. Mubin, Risk analysis for construction and operation of gas pipeline projects in Pakistan. Pakistan Journal of Engineering and Applied Sciences, 2(Jan) 2008, 22-37.

[18] Y. Guo, X. Meng, D. Wang, T. Meng, S. Liu \& R. He, Comprehensive risk evaluation of long-distance oil and gas transportation pipelines using a fuzzy Petri net model, J. of Natural Gas Science and Engineering, 33 (2016) 18-29.

[19] A. Yazdani-Chamzini, Proposing a new methodology based on fuzzy logic for tunnelling risk assessment, J. of Civil Engineering and Management, 20 (2014) 82-94.

[20] L. J. Cronbach, Coefficient alpha and the internal structure of tests, j. PSYCHOMETRIKA, 16 September (1951) 279-334.

[21] N. M. Webb, R. J. Shavelson \& E. H. Haertel, Reliability Coefficients and Generalizability Theory. In: Rao, C.R. \& Sinharay, S. (eds.) Handbook of Statistics (Vol.) 26. (2006), North Holland: Elsevier.

[22] J. Pallant, SPSS Survival Manual: A Step by Step Guide to Data Analysis Using SPSS, Crows Nest, NSW, Australia: Allen \& Unwin Pty. Limited, 2005. 